\title{
Need of Assistance with Daily Oral Hygiene Measures Among Nursing Home Resident Elderly Versus the Actual Assistance Received from the Staff
}

\author{
Marianne Forsell ${ }^{1}$, Petteri Sjögren ${ }^{2, *}$ and Olle Johansson ${ }^{3}$ \\ ${ }^{I}$ Oral Care AB, Stockholm, Sweden; ${ }^{2}$ Oral Care AB, Göteborg, Sweden; ${ }^{3}$ The Experimental Dermatology Unit, Depart- \\ ment of Neuroscience, Karolinska Institute, Stockholm, Sweden
}

\begin{abstract}
The aim was to evaluate the need of assistance with daily oral hygiene measures among nursing home resident elderly versus the actual assistance received from the staff. The need of daily oral hygiene assistance was assessed descriptively for nursing home resident elderly who participated in an annual oral health screening in three geographical regions in Sweden, in the year 2008. All individuals of age $\geq 65$ years were included $(\mathrm{n}=22,453 ; 6,327$ men; 16,126 women). The proportion of individuals in need of assistance with daily oral hygiene measures was $77.5 \%(n=22,453)$, whereas the proportion of individuals receiving assistance with daily oral hygiene measures was $6.9 \%$ in total $(n=22,453)$. The proportions were largely similar in all geographical regions. There seems to be a large discrepancy between the need of assistance with daily oral hygiene measures, and the oral hygiene assistance received, among nursing home resident elderly.
\end{abstract}

\section{INTRODUCTION}

In the current Swedish public dental health insurance system the cost of dental care for community dwelling elderly and disabled patients, as well as for certain other prioritized groups of the Swedish population, is extensively subsidized by the Swedish County Councils [1]. Therefore, patients belonging to any of the subsidized categories are entitled to receive a free-of-charge, annual oral health screening.

Within the current public dental health insurance system it is also considered important that an unbiased provider/purchaser relation is maintained. Thus, regional private entrepreneurs as well as public dental services have procured the missions of oral health screenings from the different County Councils in Sweden.

Elderly patients in nursing homes often have poor oral health due to difficulties to maintain a sufficient level of personal oral hygiene, as well as difficulties to access professional dental care [2]. Many of the nursing home resident elderly suffer from dementia. An increasing volume of scientific publications indicate a relationship between oral infections and general health complications among elderly and medically compromised individuals [3-5], and there are strong research data available for an association between insufficient oral hygiene and health care-associated pneumonia among hospitalized and nursing home resident elderly [6, 7]. Therefore, it is considered important to ensure that the nursing home staff provides dependent elderly with adequate oral hygiene measures on a daily basis [8-10]. In this context, it is also important to evaluate the need of assistance with oral hygiene measures from the dental professionals' point of view.

*Address correspondence to this author at the Oral Care AB, Drottninggatan 13, SE-411 14 Göteborg, Sweden; Tel: +46 3178032 50; Fax: +46 3113 85 15; E-mail: petteri.sjogren@oralcare.se
Since we could not locate any previous studies in this particular area, this study was initiated with the aim to elucidate the need of assistance with daily oral hygiene measures among nursing home resident elderly, versus the actual assistance received from the nursing staff.

\section{MATERIALS AND METHODOLOGY}

Oral health screening data from all individuals, at least 65-years old, living in nursing homes (including service apartments for elderly, and excluding group residences for disabled or for psychiatric patients), in the Skåne Region, the Stockholm County, and the Västra Götaland Region, in Sweden, who approved an annual, routinely conducted, oral health screening, between the period 2008-01-01--10-22, were included. The need of assistance with daily oral hygiene measures was determined by dental hygienists, trained in conducting oral health screenings for the elderly (Oral Care AB, Göteborg, Malmö, and Stockholm, Sweden). The need of assistance was based on the individual oral hygiene status among the nursing home resident elderly. Before the data collection, all dental hygienists were trained to use a four grade oral hygiene scale. Briefly: 1 = 'good oral hygiene' (i.e. no visible biofilm on teeth or dentures); 2 = 'acceptable oral hygiene' (i.e. only small amounts of biofilm on tooth surfaces difficult to brush, or on dentures); 3 = 'inadequate oral hygiene' (visible biofilm on tooth surfaces, or on dentures); 4 = 'poor oral hygiene' (persistent biofilm on teeth, or on dentures, or food debris in oral cavity). For every individual the dental hygienists' overall professional judgment led to the decision of whether assistance with daily oral hygiene from the nursing staff was deemed necessary or not.

Whenever the residents could not speak for themselves (e.g. dementia patients), the nursing personnel answered if the individual received assistance with daily oral hygiene measures. The data were collected with a mobile personal digital assistant (MobilDent, Oral Care AB, Stockholm, 
Table 1. Sample Distribution by Gender Among Nursing Home Resident Elderly in the Skåne Region, the Stockholm County, the Västra Götaland Region, and in Total, in the Year 2008 (Percentage Per Geographical Region within Parenthesis)

\begin{tabular}{|c|c|c|c|c|}
\hline Gender & $\begin{array}{c}\text { Skåne } \\
\text { Region } \\
(\mathbf{n}=6, \mathbf{5 2 2})\end{array}$ & $\begin{array}{c}\text { Stockholm } \\
\text { County } \\
(n=7,678)\end{array}$ & $\begin{array}{l}\text { Västra Götaland Region } \\
\qquad(\mathrm{n}=\mathbf{8 , 2 5 3 )}\end{array}$ & $\begin{array}{c}\text { Total } \\
\text { Sample } \\
(\mathbf{n}=\mathbf{2 2 , 4 5 3})\end{array}$ \\
\hline Men & $1,789(27.4)$ & $2,026(26.4)$ & $2,512(30.4)$ & $6,327(28.2)$ \\
\hline Women & $4,733(72.6)$ & $5,652(73.6)$ & $5,741(69.6)$ & $16,126(71.8)$ \\
\hline
\end{tabular}

Table 2. Need of Assistance with Daily Oral Hygiene, and Assistance Received, Among Elderly Living in nursing homes (n=6,522) in the Skåne Region in the Year 2008 (Percentage of Total Within Parenthesis)

\begin{tabular}{|c|c|c|c|c|}
\hline Age (yrs.) & $\begin{array}{c}\text { No Need of } \\
\text { Assistance } \\
(\mathbf{n = 1 , 8 0 0})\end{array}$ & $\begin{array}{c}\text { Needs } \\
\text { Assistance } \\
(\mathbf{n = 4 , 7 2 2})\end{array}$ & $\begin{array}{c}\text { Receives } \\
\text { Assistance } \\
(\mathbf{n = 5 1 9})\end{array}$ \\
\hline \hline $65-69$ & $59(0.9)$ & $92(1.4)$ & 151 & $14(0.2)$ \\
\hline $70-74$ & $72(1.1)$ & $198(3.0)$ & 270 & $24(0.4)$ \\
\hline $75-79$ & $163(2.5)$ & $443(6.8)$ & 1,259 & $58(0.9)$ \\
\hline $80-84$ & $349(5.4)$ & $910(14.0)$ & 1,925 & $97(1.5)$ \\
\hline $85-89$ & $515(7.9)$ & $1,410(21.6)$ & 1,601 & $162(2.5)$ \\
\hline $90-94$ & $448(6.9)$ & $1,153(17.7)$ & 710 & $119(1.8)$ \\
\hline $95-$ & $194(3.0)$ & $516(7.9)$ & $45(0.7)$ \\
\hline
\end{tabular}

Sweden), and were electronically stored in a secure database server [11]. The data were compiled from the database by an independent program developer at AdHoc Systems AB (Lund, Sweden), and tabulated in Excel (Microsoft) spreadsheets. The manuscript and the Excel spreadsheets were independently analyzed at the Department of Learning, Informatics, Management and Ethics, The Medical Statistics Service Group, the Karolinska Institute, Stockholm, Sweden.

\section{RESULTS}

Out of all eligible individuals $(n=24,700)$ for the oral health screening, 1,652 declined to participate, and 595 were not available when the screening took place. Thus, the final sample consisted of 22,453 nursing home resident elderly (age range: 65-108 yrs; 6,327 men; 16,126 women) (Table 1).

Natural teeth, or residual roots were seen in $68 \%$ of the included nursing home resident elderly $(\mathrm{n}=22,453)$, and 36 $\%$ had (one or two) complete removable dentures, whereas $13 \%$ had removable partial dentures. One or several dental implants were seen in $4 \%$ of the individuals.

The proportions of individuals in need of assistance with daily oral hygiene measures were $77.5 \%$ in total $(n=22,453)$, $72.4 \%$ in the Skåne Region ( $\mathrm{n}=6,522$; age range: 65-106 yrs), $71.5 \%$ in the Stockholm County ( $n=7,678$; age range: 65-108 yrs), and $87.1 \%$ in the Västra Götaland Region $(\mathrm{n}=8,253$; age range: $65-108 \mathrm{yrs})$, whereas the proportions of individuals receiving assistance with daily oral hygiene measures were $6.9 \%$ in total $(\mathrm{n}=22,453), 8.0 \%$ in the Skåne Region $(\mathrm{n}=6,522), 2.2 \%$ in the Stockholm County $(\mathrm{n}=7,678)$, and $10.3 \%$ in the Västra Götaland Region $(\mathrm{n}=8,253)$.

The largest numbers of individuals in total, and in need of assistance, as well as individuals receiving assistance with daily oral hygiene measures, were seen in the age group 85 89 years in all regions (Tables $\mathbf{2 - 4}$ ).

The proportions of individuals in need of assistance within the different age groups were largely similar in the Skåne Region and the Stockholm County, but a tendency towards higher proportions was seen in the Västra Götaland Region (Tables 2-4).

A trend towards higher proportions of individuals receiving assistance with daily oral care within the different age groups was seen in the Västra Götaland Region, followed by the Skåne Region, and being the lowest in the Stockholm County (Tables 2-4).

The proportions of individuals in need of assistance with daily oral care, and individuals receiving assistance with daily oral hygiene measures, were largely similar for men and women in all regions (data not shown).

\section{DISCUSSION}

The aim of this study was to evaluate the need of assistance with daily oral hygiene measures among nursing home resident elderly, versus the actual assistance received from the nursing personnel.

The sample consisted of all nursing home resident elderly that underwent an annual, routinely conducted, oral health screening during the study period. The assessments were 
Table 3. Need of Assistance with Daily Oral Hygiene, and Assistance Received, Among Elderly Living in Nursing Homes (n=7,678) in the Stockholm County in the Year 2008 (Percentage of Total Within Parenthesis)

\begin{tabular}{|c|c|c|c|c|}
\hline Age (yrs.) & $\begin{array}{c}\text { No Need of } \\
\text { Assistance } \\
(\mathbf{n = 2 , 1 8 9 )}\end{array}$ & $\begin{array}{c}\text { Needs } \\
\text { Assistance } \\
(\mathbf{n = 5 , 4 8 9})\end{array}$ & $\begin{array}{c}\text { n per } \\
\text { Age Group } \\
\text { Assistance } \\
(\mathbf{n = 1 6 9})\end{array}$ & $5(0.1)$ \\
\hline \hline $65-69$ & $56(0.7)$ & $105(1.4)$ & 354 & $9(0.1)$ \\
\hline $70-74$ & $105(1.4)$ & $249(3.2)$ & 690 & $19(0.2)$ \\
\hline $75-79$ & $196(2.6)$ & $494(6.4)$ & 1,464 & $31(0.4)$ \\
\hline $80-84$ & $422(5.5)$ & $1,042(13.6)$ & 2,181 & $54(0.7)$ \\
\hline $85-89$ & $677(8.8)$ & $1,504(19.6)$ & 1,856 & $35(0.5)$ \\
\hline $90-94$ & $498(6.5)$ & $1,358(17.7)$ & 972 & $16(0.2)$ \\
\hline $95-$ & $235(3.1)$ & $737(9.6)$ & & \\
\hline
\end{tabular}

Table 4. Need of Assistance with Daily Oral Hygiene, and Assistance recEived, Among Elderly Living in Nursing Homes in the Västra Götaland Region $(n=8,253)$ in the Year 2008 (Percentage of Total Within Parenthesis)

\begin{tabular}{|c|c|c|c|c|}
\hline Age (yrs.) & $\begin{array}{c}\text { No need of } \\
\text { Assistance } \\
(\mathbf{n = 1 , 0 6 5})\end{array}$ & $\begin{array}{c}\text { Needs } \\
\text { Assistance } \\
(\mathbf{n = 7 , 1 8 8})\end{array}$ & $\begin{array}{c}\text { n per } \\
\text { Age Group }\end{array}$ & $\begin{array}{c}\text { Receives } \\
\text { Assistance } \\
(\mathbf{n}=\mathbf{8 5 3})\end{array}$ \\
\hline \hline $65-69$ & $27(0.3)$ & $158(1.9)$ & 185 & $18(0.2)$ \\
\hline $70-74$ & $57(0.7)$ & $303(3.7)$ & 360 & $39(0.5)$ \\
\hline $75-79$ & $82(1.0)$ & $657(8.0)$ & 739 & $86(1.0)$ \\
\hline $80-84$ & $219(2.7)$ & $1,433(17.4)$ & 2,512 & $182(2.2)$ \\
\hline $85-89$ & $323(3.9)$ & $2,189(26.5)$ & 1,935 & $239(2.9)$ \\
\hline $90-94$ & $274(3.3)$ & $1,661(20.1)$ & 870 & $201(2.4)$ \\
\hline $95-$ & $83(1.0)$ & $787(9.5)$ & $88(1.1)$ \\
\hline
\end{tabular}

conducted by the largest provider (Oral Care AB) of oral health screenings in the Skåne Region, the Stockholm County, and the Västra Götaland Region, in Sweden, in the year 2008. These three regions include both rural and urban areas, as well as the three largest cities in Sweden. Thus, we consider the sample largely representative for nursing home resident elderly in Sweden. The sample consisted of a larger number of women than men, reflecting the age distribution in the Swedish population, where a larger number of boys are born, but where women have a longer life expectancy [12]. Thus, a larger number of women are prevalent in all age groups above 65 years in the Swedish population, whereas in the age groups below 65 years men are slightly predominant [12]. Another potential reason for the uneven gender distribution is that women are more prone to adhere to health promotion programs, explaining why a larger proportion of women may have agreed to participate in the oral health screenings [13].

These data are descriptive, and derived from a database of routinely conducted oral health screenings. Thus, conclusions should be drawn with caution. However, within the limitations of this study, the obtained data indicate a large discrepancy between the professionally assessed need of assistance with daily oral hygiene measures among nursing home resident elderly, versus the actual help received from the nursing staff. This situation was largely similar for men and women and across different age groups.

Although descriptive, the data indicate that there may be differences between different geographical regions in Sweden, with a tendency towards less help received among the nursing home resident elderly in the Stockholm County, than in the Skåne Region and in the Västra Götaland Region. If this difference is valid, it may reflect different attitudes and behaviors towards oral care tasks among the nursing home staffs in different geographical regions in Sweden. However, further studies with a hypothesis testing design are needed to address this question.

In light if the available scientific evidence for a relationship between oral infections and general health complications among hospitalized or nursing home resident elderly [3-7], especially for an association between insufficient oral hygiene and health care-associated pneumonia [6, 7], the importance of sufficient assistance with oral hygiene measures for nursing home resident elderly needs to be increasingly emphasized. In addition, poor oral hygiene, as well as a poor dental status may result in reduced life quality and difficulties in maintaining an active social life [14]. At the end, 
all of this will result in large unnecessary monetary costs for the society.

The elderly population in Sweden and in other developed countries increases [12], and the nursing home resident elderly more often have their own natural teeth, as well as advanced dental prosthetic appliances (e.g. crowns, bridges, and dental implants) [15], all of which impose heavier demands on the nursing home staff, and on their skills in oral care.

Insufficient education in oral health and disease, as well as in oral hygiene, in both undergraduate and postgraduate nursing curriculae, has been recognized as a major barrier for providing adequate oral care for dependent elderly [16, 17]. Thus, more oral health-related learning and training should be included in the nursing educational programmes [16, 17], as well as novel approaches for oral hygiene education of nursing home staff.

\section{CONCLUSION}

There is a large discrepancy between the need of assistance with daily oral hygiene measures among nursing home resident individuals, versus the actual assistance received from the nursing personnel. The importance of assistance with oral hygiene measures among nursing home resident elderly needs to be increasingly emphasized.

\section{ACKNOWLEDGEMENTS}

Marianne Forsell and Petteri Sjögren were supported by Oral Care AB, Stockholm, Sweden. Olle Johansson was supported by grants from The Karolinska Institute, The Cancer and Allergy Foundation (Cancer- och Allergifonden) and the Help Foundation (Hjälpfonden).

We thank Jennie Berg at AdHoc Systems AB (Lund, Sweden) for extracting the data and Margareta Krook-Brandt at The Department of Learning, Informatics, Management and Ethics, The Medical Statistics Service Group (Karolinska Institute, Stockholm, Sweden) for critically reviewing the manuscript and the statistics.

\section{CONFLICT OF INTEREST}

The project was conducted as a research project at the dental care company Oral Care AB, Sweden. To avoid any conflicts of interest between the authors and the sponsor (Oral Care AB) the data was extracted from the database by an independent program developer at AdHoc Systems AB (Lund, Sweden). All data and results were also sent for critical review of the manuscript and the statistics at the Depart- ment of Learning, Informatics, Management and Ethics, The Medical Statistics Service Group, the Karolinska Institute, Stockholm, Sweden.

\section{REFERENCES}

[1] Swedish law. Lag (1998:554) om ändring i tandvårdslagen (1985:125). no. 1998:554. Stockholm: Riksdagen 1998.

[2] Scannapieco FA, Papandonatos GD, Dunford RG. Association between oral conditions and respiratory disease in a national sample survey population. Ann Periodontol 1998; 3: 251-6.

[3] El-Solh AA, Pietrantoni C, Okada M, Zambon J, Aquilina A, Berbary E. Colonization of dental plaques a reservoir of respiratory pathogens for hospital acquired pneumonia in institutionalized elders. Chest 2004; 126: 1575-82.

[4] Preston AJ, Gosney MA, Noon S, Martin MV. Oral flora of elderly patients following acute medical admission. Gerontology 1999; 45: 49-52.

[5] Scannapieco FA, Mylotte JM. Relationship between periodontal disease and bacterial pneumonia. J Periodontol 1996; 76: 1114-22.

[6] Azarpazhooh A, Leake JL. Systematic review of the association between respiratory diseases and oral health. J Periodontol 2006; 77: 1465-82.

[7] Sjögren P, Nilsson E, Forsell M, Johansson O, Hoogstraate J. A systematic review of the preventive effect of oral hygiene on pneumonia and respiratory tract infection in elderly in hospitals and nursing homes: effect estimates and methodological quality of randomized controlled trials. J Am Geriatr Soc 2008; 56: 2124-30.

[8] Frenkel H, Harvey I, Needs K. Oral health care education and its effect on caregivers' knowledge and attitudes: a randomised controlled trial. Commun Dent Oral Epidemiol 2002; 30: 91-100.

[9] Matear DW. Demonstrating the need for oral health education in geriatric institutions. Probe 1999; 33: 66-71.

[10] Sweeney MP, Williams C, Kennedy C, Macpherson LM, Turner S, Bagg J. Oral health care and status of elderly care home residents in Glasgow. Commun Dent Health 2007; 24: 37-42.

[11] Forsell M, Häggström M, Johansson O, Sjögren P. Personal digital assistant application (MobilDent) for dental field work data collection, information management and database handling. Br Dent $\mathrm{J}$ 2008; 205(9): E-17.

[12] Statistics Sweden 2008. Available from: http://www.scb.se/ BE0101-EN

[13] Lewis RJ, Huebner WW, Yarborough CM 3rd. Characteristics of participants and nonparticipants in worksite health promotion. Am J Health Promot 1996; 11: 99-106.

[14] Walker RJ, Kiyak HA. The impact of providing dental services to frail older adults: perceptions of elders in adult day health centers. Spec Care Dentist 2007; 27: 139-43.

[15] Hugoson A, Koch G, Göthberg C, et al. Oral health of individuals aged 3-80 years in Jönköping, Sweden during 30 years (19732003). II. Review of clinical and radiographic findings. Swed Dent J 2005; 29: 139-55.

[16] Nicol R, Sweeney PM, McHugh S, Bagg J. Effectiveness of health care worker training on the oral health of elderly residents of nursing homes. Commun Dent Oral Epidemiol 2005; 33: 115-24.

[17] Wårdh I, Andersson L, Sörensen S. Staff attitudes to oral health care. A comparative study of registered nurses, nursing assistants and home care aides. Gerodontology 1997; 14: 28-32.

Received: June 11, 2009

(C) Forsell et al.; Licensee Bentham Open.

This is an open access article licensed under the terms of the Creative Commons Attribution Non-Commercial License (http://creativecommons.org/licenses/by-nc/3.0/) which permits unrestricted, non-commercial use, distribution and reproduction in any medium, provided the work is properly cited. 